\title{
Doppler ultrasonographic evaluation of splanchnic blood flow in coeliac disease
}

\author{
V Arienti, C Califano, G Brusco, L Boriani, F Biagi, M Giulia Sama, S Sottili, \\ A Domanico, G R Corazza, G Gasbarrini
}

\author{
Patologia Medica I \\ V Arienti \\ C Califano \\ G Brusco \\ L Boriani \\ F Biagi \\ M G Sama \\ A Domanico \\ Cattedra di \\ Gastroenterologia \\ S Sottili \\ Università di Bologna, \\ Italy \\ Dipartimento di \\ Medicina Interna, \\ Università dell'Aquila, \\ Italy \\ G R Corazza \\ Cattedra di Medicina \\ Interna II - Università \\ Cattolica, Roma, Italy \\ G Gasbarrini \\ Correspondence to: \\ Dr V Arienti, \\ Patologia Medica I - \\ Università di Bologna \\ Ospedale SOrsola, via \\ Massarenti 9, 40138 \\ Bologna, Italia. \\ Accepted for publication \\ 16 April 1996
}

\begin{abstract}
Background-Current knowledge on splanchnic haemodynamics in coeliac disease is limited and incomplete.

Aim-To evaluate splanchnic arterial and venous blood flow in coeliac disease.

Methods-In 22 coeliac (13 untreated, nine treated) patients and in nine healthy subjects the following variables were assessed: vessel diameter and mean flow velocity in portal vein, splenic vein, superior mesenteric vein, and superior mesenteric artery. Peak systolic velocity, end diastolic velocity and pulsatility index were also determined in the superior mesenteric artery. Five patients of the untreated group were re-evaluated after nine months on a gluten free diet.
\end{abstract}

Results-Significant differences in haemodynamic variables between the three groups were shown only in the superior mesenteric artery. An increase in both mean flow velocity and end diastolic velocity and a reduction in pulsatility index occurred in untreated patients compared with treated patients $(p<0.002 ; p<0.04$; $\mathrm{p}<0.035)$ and with healthy controls ( $p<0.001 ; p<0.025 ; p<0.0003)$. Similar results were obtained for the five patients evaluated before and after treatment ( $p<0.03 ; p<0.02 ; p<0.03)$, in whom the mean flow velocity in the superior mesenteric vein also decreased after treatment $(p<0.05)$. No significant differences were noted between treated coeliac patients and healthy controls.

Conclusions-In untreated coeliac disease there is a hyperdynamic mesenteric circulation that decreases after treatment. (Gut 1996; 39: 369-373)

Keywords: coeliac disease, Doppler ultrasonographic evaluation, splanchnic blood flow.

Coeliac disease is characterised by damage to the mucosa of the small intestine and malabsorption of most nutrients after the introduction of cereals into the diet. Clinical presentation is typically linked to malabsorption, but can be highly variable, especially in adults.

During the active clinical phase of the disease, histology can show a flat surface, absent villi, hyperplastic crypts, and increased cellularity of the lamina propria. Changes in mucosal vascularity in coeliac disease ${ }^{1}$ can also give rise to modifications in blood flow in the small intestine. To date few studies and little information are available on splanchnic haemodynamic changes during coeliac disease..$^{2-4}$ Doppler ultrasound flowmetry has been recently validated as a non-invasive and accurate method in the assessment of both arterial $^{5-7}$ and venous ${ }^{89}$ splanchnic haemodynamics. The aim of this study was to investigate arterial and venous splanchnic Doppler variables in patients with untreated and treated coeliac disease and in healthy subjects to identify possible differences between the groups. Doppler variables were also re-evaluated in five untreated patients with coeliac disease after nine months of gluten free diet to determine the influence of treatment.

\section{Patients and methods}

\section{Patients}

Twenty two patients with coelic disease (17 women, five men, mean age 30.5 (SD 4.0), 13 untreated and nine treated, and nine healthy subjects entered the study.

In all 13 consecutive patients with untreated coeliac disease (UTCD), biopsies of the mucosa of the small intestine showed a flat mucosa. In the five patients of this group reexamined after nine months of gluten free diet, treatment induced a complete clinical, laboratory, and histological recovery.

Of the nine patients with treated coeliac disease (TCD) eight were symptom free and one reported three daily diarrhoeal episodes, abdominal bloating, and diffuse abdominal pain. They had been treated in the past with a nine month period of gluten free diet, and follow up biopsies had shown the restoration of normal mucosal morphology. Laboratory variables had been normalised and serum IgA and IgG antigliadin antibodies titres had returned to normal values or had decreased considerably.

The control group comprised nine healthy subjects (seven women, two men, mean age 29.3 (SD 0.7) matched by sex, age, and percentage of ideal body weight (IBW\%) (Table I).

Neither the healthy controls nor the patients were taking any drugs known to cause vasoactive phenomena.

The nature of the study was fully explained to each patient and informed consent was obtained from each. The study was designed and performed in accordance with the principles of the Declaration of Helsinki. 
TABLe I Patient characteristics

\begin{tabular}{|c|c|c|c|c|}
\hline & UTCD & $T C D$ & $H C$ & p Value \\
\hline $\begin{array}{l}\text { Sex } \\
\text { Age } \\
\text { IBW (\%) }\end{array}$ & $\begin{array}{l}11 \mathrm{~F} ; 2 \mathrm{M} \\
26 \cdot 9(2 \cdot 1) \\
87 \cdot 4(2 \cdot 2)\end{array}$ & $\begin{array}{r}6 \mathrm{~F} ; 3 \mathrm{M} \\
35 \cdot 7(6 \cdot 8) \\
88 \cdot 3(2 \cdot 2)\end{array}$ & $\begin{array}{r}7 \mathrm{~F} ; 2 \mathrm{M} \\
29 \cdot 3(0 \cdot 7) \\
93 \cdot 1(3 \cdot 7)\end{array}$ & $\begin{array}{l}\text { NS }\left(^{\star}\right) \\
N S\left(^{\star \star}\right) \\
N S\left({ }^{\star \star}\right)\end{array}$ \\
\hline
\end{tabular}

$\left.{ }^{\star}{ }^{\star}\right)$ Fisher's exact test.

$(\star \star)$ Kruskal-Wallis test.

\section{Methods}

In all patients and controls duplex Doppler measurements of blood flow velocities were obtained in portal vein, splenic vein, superior mesenteric vein, and superior mesenteric artery.

The following Doppler variables were evaluated: (a) the mean velocity (MV), which is a computer-derived value determined by integrating the area under each individual velocity waveform; (b) the peak systolic velocity (PSV), which represents maximum flow velocity recorded during each cardiac cycle; (c) the end diastolic velocity (EDV), which is the value recorded immediately before the next systolic upstroke and which correlates with end organ resistance to blood flow; (d) the pulsatility index (PI), according to the formula $\mathrm{PI}=\mathrm{PSV}-\mathrm{EDV} / \mathrm{MV},{ }^{10}$ which is related to the impedance of the arterial bed. ${ }^{11}{ }^{12}$ Impedence is the total resistance to flow and includes the resistance, compliance, and congestion of the vascular bed. ${ }^{13}$ If other conditions remain constant, impedence is inversely related to flow.

The pulsatility index minimises the effects of probe placements and avoids several sources of errors such as the cross sectional area of the vessel, the beam angle, the sample volume, and the curvature of the vessel. Its utility is based on the assumption that changes in resistance affect diastolic more than systolic flow velocity. ${ }^{7}$ According to the Doppler theory, flow velocity is calculated according to the following equation:

\section{$\mathrm{V}=\mathrm{Fd} \times \mathrm{C} / 2 \mathrm{Fo} \times \cos \alpha$}

where $\mathrm{Fd}$ is the Doppler shift frequency, $\mathrm{C}$ is the sound velocity in body tissue $(1540 \mathrm{~m} / \mathrm{s})$, Fo is the emitted ultrasonic wave frequency, $\alpha$ is the angle between ultrasonic beam and longitudinal axis of the vessels. In this study $\alpha$ was maintained at $30^{\circ}-60^{\circ}$. Frequency data were converted to velocity data using the software within the instrument.

The MV was determined in the portal vein, splenic vein, superior mesenteric vein, and superior mesenteric artery. In the last vessel the PSV, EDV, and the PI were also assessed. The portal vein was visualised at the midpoint of the portal trunk, the splenic vein and superior mesenteric vein at $2 \mathrm{~cm}$ from the confluence, the superior mesenteric artery in the first part, near its origin from the aorta, where its course was more linear. All the vessels were visualised in longitudinal axis and the sample volume was positioned in the centre of the vessels and was at least two thirds of the vessel diameter. Each vessel was studied for about five minutes and the Doppler trace was always recorded three times, each longer than five seconds, to obtain a reproducible range of blood flow and to average any venous flow fluctuations. Mean velocity was calculated as a mean of three consecutive measurements. In the five patients re-evaluated after treatment ultrasonographic pictures of previous examinations were used to reproduce the same ultrasonographic section, sample volume, and insonation angle. The echo Doppler feasibility of various vessels was $100 \%$ for portal vein, $87 \%$ for splenic vein, $81 \%$ for superior mesenteric vein, and $100 \%$ for superior mesenteric artery. The results of echo Doppler feasibility were not statistically different between the three groups.

To avoid the influence of meals, ${ }^{14}$ exercise, and postural changes ${ }^{91516}$ on splanchnic haemodynamics and to exclude the effects of respiratory cycles, Doppler ultrasound investigations were performed in all patients after an overnight fast, at rest, in the supine position, and during quiet respiration.

Arterial pressure at the left forearm, arterial pulse at the radial artery, arterial Doppler variables at the right femoral artery, and the diameter of all the vessels considered were also measured.

All the variables mentioned above were reassessed after nine months of gluten free diet in five patients of the untreated group.

The Doppler data (mean velocity, peak systolic velocity, end diastolic velocity, and pulsatility index) were calculated by the same ultrasound system and all the duplex Doppler studies were performed by the same skilled sonographer (CC), with more than four years of experience. In our ultrasonographic laboratory the variation between two operators (VA and $\mathrm{CC}$ ) and the intraobserver variation (CC) were $<6 \%$ and $<4 \%$ respectively.

\section{Equipment}

Ultrasonographic investigations were performed using a real time instrument (Toshiba Sonolayer SSH-140A) provided by Doppler and colour Doppler devices with a $3.75 \mathrm{MHz}$ convex probe and $5 \mathrm{MHz}$ linear probe.

\section{Statistical analysis}

The results were reported as means (SEM). All the variables studied of the three groups were evaluated with the Kruskal-Wallis test. Comparisons between untreated patients with coelic disease, treated patients with coeliac disease, and healthy subjects were made with the Mann-Whitney $U$ test with Bonferroni correction. The data from the five patients with coeliac disease studied before and after nine months of gluten free diet were analysed by Student's $t$ test for paired data. ${ }^{17}$

Statistical analysis was performed with the statistical analysis system (SAS) version $6 \cdot 04 .{ }^{18}$

\section{Results}

The analysis of the Doppler variables, in the three groups (untreated patients with coeliac disease, treated patients with coeliac disease, and healthy controls) showed statistical differ- 
TABLE II Values of the Doppler variables (mean (SEM))

\begin{tabular}{|c|c|c|c|c|c|c|}
\hline \multirow{2}{*}{$\begin{array}{l}\text { Doppler } \\
\text { variables } \\
(\mathrm{m} / \mathrm{s})\end{array}$} & \multicolumn{3}{|c|}{ Blood flow velocities } & \multicolumn{3}{|l|}{$p$ Value $^{\star}$} \\
\hline & UTCD & $T C D$ & $H C$ & $U T C D v T C D$ & $U T C D v H C$ & $T C D v H C$ \\
\hline $\begin{array}{l}\text { MVpv } \\
\text { MVsv } \\
\text { MVsmv } \\
\text { MVsma } \\
\text { PSVsma } \\
\text { EDVsma } \\
\text { Plsma } \\
\text { MVrfa } \\
\text { PSVrfa } \\
\text { EDVrfa } \\
\text { Plrfa }\end{array}$ & $\begin{array}{l}0.20(0.01) \\
0.16(0.01) \\
0.23(0.01) \\
0.56(0.04) \\
1.07(0.008) \\
0.22(0.03) \\
1.58(0.14) \\
0.28(0.03) \\
0.98(0.05) \\
0.26(0.04) \\
4.81(0.08)\end{array}$ & $\begin{array}{l}0.19(0.01) \\
0.18(0.01) \\
0.22(0.02) \\
0.36(0.02) \\
0.88(0.04) \\
0.12(0.01) \\
2.17(0.16) \\
0.31(0.01) \\
1.14(0.08) \\
0.22(0.01) \\
5.01(0.02)\end{array}$ & $\begin{array}{l}0.22(0.01) \\
0.19(0.01) \\
0.21(0.01) \\
0.33(0.02) \\
0.98(0.06) \\
0.10(0.02) \\
2.62(0.13) \\
0.28(0.02) \\
1.10(0.02) \\
0.24(0.03) \\
4.76(0.20)\end{array}$ & $\begin{array}{l}\text { NS } \\
\text { NS } \\
\text { NS } \\
<0 \cdot 002 \\
\text { NS } \\
<0 \cdot 04 \\
<0 \cdot 035 \\
\text { NS } \\
\text { NS } \\
\text { NS } \\
\text { NS }\end{array}$ & $\begin{array}{l}\text { NS } \\
\text { NS } \\
\text { NS } \\
<0 \cdot 001 \\
\text { NS } \\
<0 \cdot 025 \\
<0 \cdot 0003 \\
\text { NS } \\
\text { NS } \\
\text { NS } \\
\text { NS }\end{array}$ & $\begin{array}{l}\text { NS } \\
\text { NS } \\
\text { NS } \\
\text { NS } \\
\text { NS } \\
\text { NS } \\
\text { NS } \\
\text { NS } \\
\text { NS } \\
\text { NS } \\
\text { NS }\end{array}$ \\
\hline
\end{tabular}

Kruskal-Wallis test and, when $\mathrm{p}<0.05$, Mann-Whitney $U$ test with Bonferroni correction. $\mathrm{pv}=$ portal vein; $\mathrm{sv}=$ splenic vein; $\mathrm{smv}=$ superior mesenteric vein; sma=superior mesenteric artery; rfa=right femoral artery. For other abbreviations see Table I.

ences only in the superior mesenteric artery (MV, p<0.0001; EDV, p<0.008; PI, $\mathrm{p}<0.0001$. No statistical differences were found in the portal vein, the splenic vein, or the superior mesenteric vein. In the last vessel, although not statistically significant, the absolute value of $M V$ for the superior mesenteric vein was greater in untreated patients $(0.23(0.01) \mathrm{m} / \mathrm{s})$ than in treated patients with coeliac disease $(0.22(0.02) \mathrm{m} / \mathrm{s})$ or healthy controls $(0.21(0.01) \mathrm{m} / \mathrm{s})$.
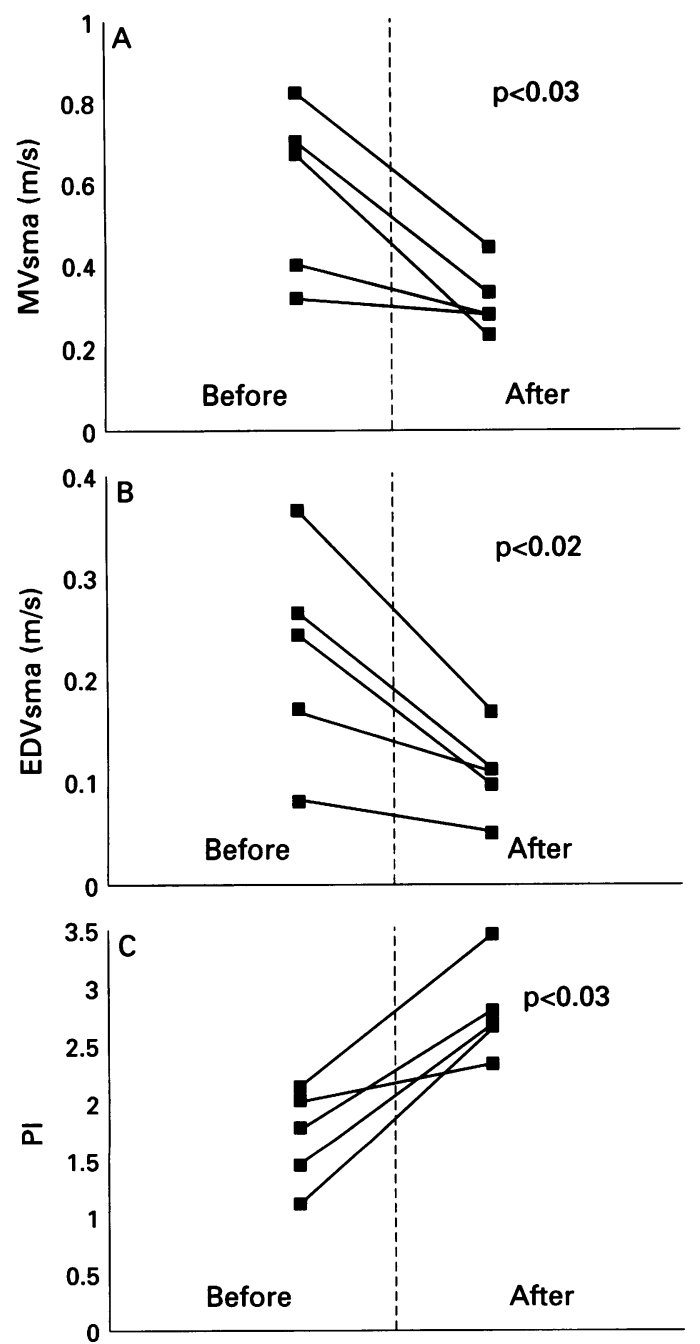

Figure 1: (A) Mean velocity (MV), (B) end diastolic velocity $(E D V)$, and $(C)$ pulsatility index $(P I)$ in the superior mesenteric artery (sma), in five patients evaluated when untreated and after nine months of gluten free diet.
The comparison between the groups showed that both $M V$ and EDV in the superior mesenteric artery were significantly higher in untreated patients with coeliac disease than in treated patients $(p<0.002 ; p<0.04)$ or healthy subjects $(p<0.001 ; p<0.025)$. Moreover, in the superior mesenteric artery PI was significantly lower in untreated patients with coeliac disease than in treated patients with coeliac disease $(p<0.035)$ or healthy subjects $(p<0.0003)$ (Table II).

In the five untreated patients with coeliac disease, re-evaluated after nine months of gluten free diet, both MV $(p<0.03)$ and EDV $(p<0.02)$ decreased and PI $(p<0.03)$ increased in the superior mesenteric artery (Figs 1 and 2). In this group of patients, mean velocity in the superior mesenteric vein significantly decreased after treatment $(p<0.05)$ (Fig 3).

The flow velocities in the right femoral artery, the diameter of all the vessels studied, the arterial pressure, and the arterial pulse did not differ in the three groups (Table III).

\section{Discussion}

Among the few techniques that are commonly used for clinical studies of intestinal blood flow, Doppler ultrasound can be considered an ideal method. In fact it is safe, non-invasive, accurate, quantitative, and reproducible; it respects the physiological conditions, and it does not alter blood flow. Doppler ultrasound flowmetry has in recent years received increasing interest for the investigation of splanchnic haemodynamics both in physiological $^{914}$ and pathological conditions, such as portal hypertension, inflammatory bowel diseases, and intestinal angina. ${ }^{19-21}$ However, little information exists on intestinal blood flow in coeliac patients. A previous angiographic study suggested a shortened intestinal circulation time. ${ }^{2}$ Recently, two studies have evaluated splanchnic haemodynamics, by pulsed Doppler flowmetry, in patients affected by coeliac disease. The first one studied only the superior mesenteric vein in three coeliac patients and disclosed a high blood flow velocity in this vessel that decreased and normalised only two months after the starting of the gluten withdrawal diet. ${ }^{3}$ The second studied only the superior mesenteric artery; it showed an increased and delayed postprandial blood flow in coeliac patients with respect to controls and a reduced flow to normal values in four patients re-examined after treatment. ${ }^{4}$

In our study we evaluated the possible effects of coeliac disease on splanchnic haemodynamics and in particular on blood flow velocity in the portal vein, splenic vein, superior mesenteric vein, and superior mesenteric artery. The results showed that in untreated coeliac disease definite variations of blood flow velocity occurred only in the mesenteric circulation, whereas the flow velocity in portal and splenic veins remained nearly constant. Moreover, systemic haemodynamics, evaluated by arterial blood pressure, arterial pulse, and blood flow velocities in right femoral artery did not differ in the three groups. 


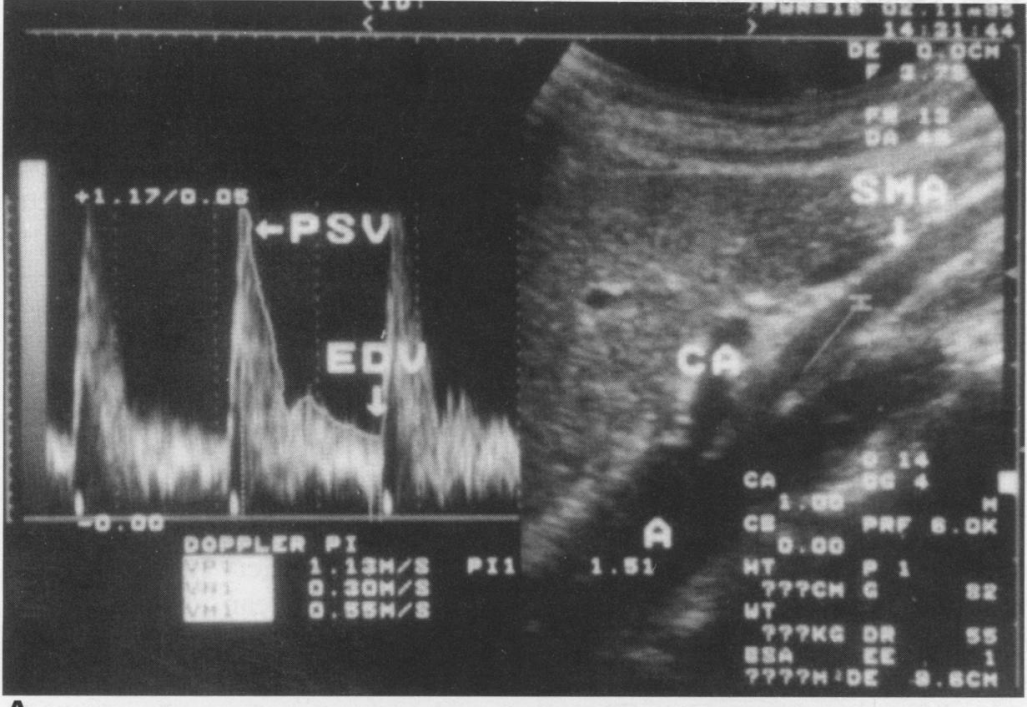

A

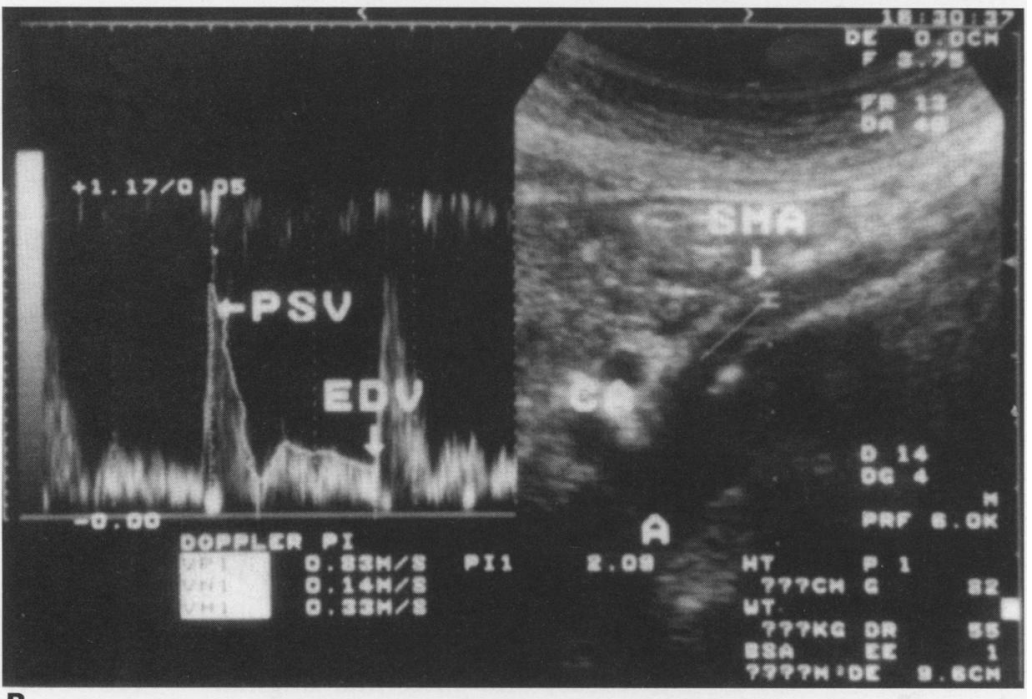

Figure 2: Doppler spectra waveform in superior mesenteric artery in a patient evaluated $(A)$ before and $(B)$ after treatment.

In the superior mesenteric artery both the mean flow velocity and the diastolic component of the Doppler spectra waveform were significantly higher in untreated coeliac patients than in treated coeliac patients or healthy controls, whereas PI was significantly lower in the untreated coeliac patients than in treated coeliac patients or healthy controls. Only the systolic component of arterial blood flow did not change between the three groups. The same data were also confirmed by comparing the Doppler variables in the five patients evaluated before and after nine months of gluten free diet. The treatment resulted in a

TABLE III Vessel diameter, arterial pressure, and arterial pulse (mean (SEM))

\begin{tabular}{|c|c|c|c|c|}
\hline & $U T C D$ & $T C D$ & $H C$ & $p$ Value $^{\star}$ \\
\hline $\mathrm{Dpv}(\mathrm{mm})$ & $9 \cdot 45(0 \cdot 20)$ & $8.50(0.64)$ & $9.05(0.30)$ & NS \\
\hline Dsv (mm) & $5.55(0.32)$ & $5.42(0.33)$ & $5.60(0.50)$ & NS \\
\hline Dsmv (mm) & $7.67(0.48)$ & $6.90(0.37)$ & $6.53(0.35)$ & NS \\
\hline $\mathrm{Dsma}(\mathrm{mm})$ & $5.54(0.19)$ & $5.66(0.27)$ & $5.43(0.17)$ & NS \\
\hline Drfa (mm) & $6.91(0.21)$ & $7.01(0.01)$ & $6 \cdot 61(0.18)$ & NS \\
\hline $\mathrm{SAP}(\mathrm{mm} \mathrm{Hg})$ & $127(1.03)$ & $129(3.01)$ & $128(2 \cdot 04)$ & NS \\
\hline $\mathrm{DAP}(\mathrm{mm} \mathrm{Hg})$ & $82(2 \cdot 04)$ & $85(1 \cdot 27)$ & $80(1 \cdot 17)$ & NS \\
\hline Pulse (beats $/ \mathrm{min}$ ) & $69(0 \cdot 15)$ & $70(1.04)$ & $72(1.55)$ & NS \\
\hline
\end{tabular}

Kruskal-Wallis test.

$\mathrm{D}=$ diameter; $\mathrm{SAP}=$ systolic arterial pressure; $\mathrm{DAP}=$ diastolic arterial pressure. For other $\mathrm{D}=$ diameter; $\mathrm{SAP}=$ systolic
abbreviations see Table I.

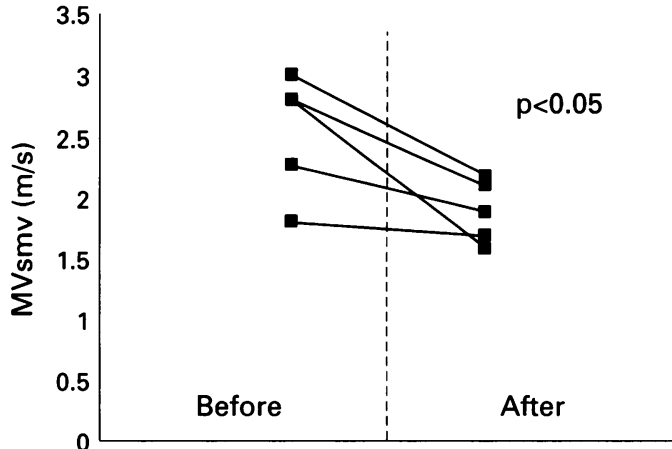

Figure 3: Mean velocity (MV) in the superior mesenteric vein (smv) evaluated before and after treatment.

reduction of both mean flow velocity and end diastolic flow velocity and an increase in PI in the superior mesenteric artery.

The higher blood flow velocity in the superior mesenteric artery of untreated coeliac patients is also reflected in the venous bed. The mean flow velocity in the superior mesenteric vein was higher in untreated patients with coeliac disease than in treated patients with coeliac disease or healthy controls although the difference was not significant. This lack of significance could be due to the greater difficulty in visualising the superior mesenteric vein and in obtaining a proper Doppler angle of insonation. In fact, in the five patients re-examined after treatment in whom it was always possible to obtain adequate Doppler traces, the mean flow velocity in the superior mesenteric vein significantly decreased after the nine month period of gluten free diet. This result, although found in a small series of patients, is more precise and accurate because it is not influenced by variations between patients.

All these data show that intestinal hyperaemia and hyperdynamic mesenteric circulation occur in coeliac disease due to the reduction of resistance. The cause of the drop in resistance is not yet well established, but an important role can be attributed to the structural rearrangement of intestinal mucosa during coeliac disease.

It is well known that absorption, secretion, and motility functions of the small intestine are localised in the mucosa, submucosa and muscular layers respectively. Eighty per cent of total intestinal blood flow is distributed to the mucosa-submucosa, presumably reflecting the higher metabolic demand of these layers, and the blood flow to the villi and crypts, estimated using radioactive microspheres and indicator dilution techniques, accounts for $24 \%-37 \%$ and $21 \%-27 \%$ respectively. ${ }^{22} 23$

From the anatomopathological point of view, the typical lesion in coeliac disease involves the mucosal layer of the small intestine, with the submucosa, muscular layers, and serosa being spared. The mucosal alteration is characterised by a complete loss of intestinal villi, a flat absorptive surface, a pronounced crypt hyperplasia and a superficial network of vessels that replaces the normal arrangement of capillaries. The glandular mucosa contains a greater number of vessels with increased tortuosity and more anastomoses than normal. ${ }^{1}$ 
Among the various intrinsic vasoregulatory phenomena of the gastrointestinal tract such as myogenic factors, metabolic mechanism, vasoactive peptides, hormones, and autacoids, the myogenic control system is generally considered to be the most important autoregulatory phenomena and its influence on the intestinal circulation is well documented. ${ }^{24-28}$ The site of autoregulation in the intestine has been localised to the precapillary resistance vessels, ${ }^{27}$ and the increased vascular resistance, found during increased venous pressure, is the result of intense precapillary constriction. ${ }^{29}$

When atrophy of the villus occurs in coeliac disease, the underlying microcirculation and the myogenic control system, localised at the arterioles and precapillary sphincter level, are consequently greatly altered. The changes of the mucosal vasculature - that is, the superficial network of vessels - and the increase of arteriovenous shunts, cause a loss in precapillary muscular tone. This determines a drop in intestinal resistance and consequently an increase in mesenteric blood flow velocity in both the arterial and venous beds. This may represent the physiopathological mechanism that explains the results of our study.

Another factor to consider as a possible mechanism is the inflammation of the intestinal wall. In coeliac disease, the surface epithelium is infiltrated with intraepithelial lymphocytes and the lamina propria is infiltrated with increased numbers of plasma cells, lymphocytes, eosinophils, and mast cells. ${ }^{30}$ This relevant inflammatory component can contribute to the pathogenesis of hyperaemia and to the determination of the hyperdynamic circulation. ${ }^{20}$ On the other hand, a recent study in an animal model of ulcerative colitis showed the non-participation of vasoactive agents derived from neutrophils in the pathogenesis of increased blood flow. ${ }^{31}$

In conclusion, these data showed that in untreated coeliac disease: (a) a hyperdynamic mesenteric circulation is present; $(b)$ the increase of mesenteric blood flow velocity is due to the increase of diastolic component in the arterial bed and of mean flow velocity in the venous bed; $(c)$ these haemodynamic changes are easily assessed by Doppler ultrasound, $(d)$ they are due to a drop in resistance, and $(e)$ they are linked to the clinical phase of the disease and normalise within nine months of gluten free diet.

We gratefully acknowledge Susan West for help in translating the manuscript and Ricerca in Medicina for financial support.

1 Cooke WT, Holmes GKT. Celiac disease. Edinburgh, Scotland: Churchill Livingstone, 1984: 27-8.

2 Gustafson T, Sjolund K, Berg NO. Intestinal circulation in celiac disease: an angiographic study. Scand $\mathcal{f}$ Gastroenterol 1982; 17: 881-5.
3 Bolondi L, Li Bassi S, Gaiani S, Zironi G, Paparo GF, Barbara L. Changes in mesenteric venous flow due to celiac sprue. Dig Dis Sci 1992; 37: 925-8.

4 Alvarez D, Vazquez H, Bai JC, Mastai R, Flores D, Boerr L. Superior mesenteric artery blood flow in celiac disease. Dig Dis Sci 1993; 38: 1175-82.

5 Qamar MI, Read AE, Skidmore R, Evans JM, Wells PNT. Transcutaneous Doppler ultrasound measurement of superior mesenteric artery blood flow in man. Gut 1986; 27: $100-5$.

6 Sato S, Ohnishi K, Sugita S, Okuda K. Splenic artery and superior mesenteric artery blood flow: non-surgical superior mesenteric artery blood flow: non-surgical Doppler US measurement in healthy subjects and patients

7 Taylor GA. Blood flow in the superior mesenteric artery: estimation with Doppler US. Radiology 1990; 174: 15-6.

8 Moriyasu F, Ban N, Nishida O, Nakamura T, Miyake T, Uchino $\mathrm{H}$, et al. Clinical application of an ultrasonic duplex system in the quantitative measurement of portal blood flow. 7 Clin Ultrasound 1986; 14: 579-88.

9 Brown HS, Halliwel M, Qamar M, Read AE, Evans JM, Wells PNT. Measurement of normal portal venous blood flow by Doppler ultrasound. Gut 1989; 30: 503-9.

10 Gosling RG, King DH, Newman DL, Woodcock JP. Transcutaneous measurement of arterial blood velocity by ultrasound. In: Ultrasonics for industry conference papers. ultrasound. In: Ultrasonics for industry

?? Planiol T, Purcelot L, Pottier JM, Degiovanni E. Etude de la circulation carotidienne par les methodes ultrasoniques et la termographie. Rev Neurol 1972; 26: 127-41.

11 Norris CS, Pfeiffer JS, Rittgers SE, Barnes RW. Noninvasive evaluation of renal artery stenosis and renovascular resistance: experimental and clinical studies. $f$ Vasc Surg 1984; 1: 192-201.

12 Barbara L. The value of Doppler US in the study of hepatic hemodynamics. $\mathcal{f}$ Hepatol 1990; 10: 353-55.

13 Moneta GL, Taylor DC, Helton S, Mulholland MW, Strandness DE. Duplex ultrasound measurement of postprandial intestinal blood flow: effect of meal composition. Gastroenterology 1988; 95: 1294-301.

14 Qamar MI, Read AE. Effects of exercise on mesenteric blood flow in man. Gut 1987; 28: 583

15 Ohnishi K, Saito M, Nakaiama T, Iida S, Nomura F, Koen H, et al. Portal venous hemodynamics in chronic liver disease: effects of posture change and exercise. Radiology 1985; 155: 757-61.

16 Glantz SA. Statistica per discipline bio-mediche. 2nd ed. Milano, Italy: McGraw Hill, 1988: 223-31.

17 SAS Institute Inc. SAS User's guide: statistics, version 5 ed. Cary, NC, USA: SAS, 1985: 795-800.

18 Burns P, Taylor K, Blei AT. Doppler flowmetry and portal hypertension. Gastroenterology 1987; 92: 824-6.

19 Bolondi L, Gaiani S, Brignola C, Campieri M, Rigamonti A, Zironi G, et al. Changes in splanchnic haemodynamics in inflammatory bowel disease. Non-invasive assessment by Doppler ultrasound flowmetry. Scand $\mathcal{f}$ Gastroenterol 1992; 27: 501-7.

20 Jager KA, Fortner GS, Thiele BL, Strandness DE. Non invasive diagnosis of intestinal angina. $\mathcal{F}$ Clin Ultrasound 1984; 12: 588-91.

21 Lifson N, Sircar B, Levitt DG, Lender EJ. Heterogeneity of macroscopic and single villus blood flow in rabbit small of macroscopic and single villus blood flow

22 Biber B, Lundgren O, Svanvik J. Intramural blood flow and blood volume in the small intestine of the cat as analyzed by an indicator dilution technique. Acta Physiol Scand 1973; 87: 391-403.

23 Johnson PC. Origin, localization and homeostatic significance of autoregolation in the intestine. Circ Res 1964; (suppl 14-15): 225-33.

24 Johnson PC. Myogenic nature of increase in intestinal vascular resistance with venous pressure elevation. Circ Res 1959; 6: 992-9.

25 Folkow B. Intravascular pressure as a factor regulating the tone of small vessels. Acta Physiol Scand 1949; 17: 289-316.

26 Johnson PC, Hanson KM. Effect of arterial pressure on arterial and venous resistance of intestine. $\mathcal{f}$ Appl Physiol 1962; 17: 503-8.

27 Hanson KM, Johnson PC. Evidence for local arterial venous reflex in intestine. $\mathcal{F}$ Appl Physiol 1962; 17: 509-13.

28 Johnson PC. Effect of venous pressure on mean capillary pressure and vascular resistance in the intestine. Circ Res 1965; 16: 294-300.

29 Marsh MN, Hinde J. Inflammatory component of celiac sprue mucosa: I mast cells, basophils and eosinophils. Gastroenterology 1985; 89: 92 .

30 Sekisuka E, Grisham MB, Li M, Deitch EA, Granger DN. Inflammation-induced intestinal hyperemia in the rat: role of neutrophils. Gastroenterology 1988; 95: 1528-34. 